\title{
Análise através da audição: uma abordagem analítica cognitiva
}

\author{
Analysis through audition: a cognitive analytical approach
}

por Jorge A. Falcón

\begin{abstract}
RESUMO
e musical baseada na percepção auditiva" que desenvolve uma leitura das configurações da superfície musical, em procura de processos estruturais de organização da matéria sonora na música. Consideram-se, em primeira instância, os princípios cognitivos de organização e de categorização e os limites da cognição humana. Desenvolvem-se depois os quatro critérios, utilizando-se de exemplos para demonstrar a sua aplicabilidade a diversos gêneros musicais.
\end{abstract}

Palavras-chave Análise Musical; Cognição; Percepção Auditiva

\begin{abstract}
This article analyzes the theoretical-technical publication entitled "Pequena Arte da ExThis work is based on the Master's Degree dissertation named "Four criteria for the musical analysis based in the auditory perception" that develops a reading of the configurations of the musical surface, in search of structural processes of organization in music. The cognitive principles of organization and categorization and the limits of the cognition are considered in first instance. After that, the four criteria are developed, and examples are applied to demonstrate its usefulness for different musical genres.
\end{abstract}

Keywords Musical Analysis; Cognition; Auditory Perception 


\section{Introdução}

No trabalho de referência "Quatro critérios para a análise musical baseada na percepção auditiva" (Falcón, 2011) procura-se fornecer alguns critérios analíticos direcionados à compreensão do fenômeno musical a partir da mais elementar forma de abordagem possível: a escuta musical. Partindo desta idéia, foi necessário um estudo direcionado à compreensão dos processos mentais destinados à interpretação, organização, estruturação, categorização, entre outros, dos estímulos externos percebidos pelo sentido da audição. Por sua vez, encontra-se um correlato no trabalho de Thoresen (2007) denominado Sonologia Aural (Aural sonology) por compartilharem uma série de pontos de partida como: a visão estruturalista e fenomenológica e o trabalho sobre a música baseado exclusivamente na audição. É necessário ressaltar que a gramática gerativa de Chomsky, a análise schenkeriana, a Gerative Theory of Tonal Music de Lerdahl e Jackendoff e a Teoria da Otimalidade de Prince e Smolensky são referências básicas deste trabalho. As primeiras porque compartilham algumas bases como a existência de profundidade (no sentido de planos hierárquicos) na música, a idéia de uma gramática musical, o reducionismo e por considerar que a música é um sistema que possui uma estrutura subjacente'; e a última porque pode ser pensada como a função que mapeia as formas existentes de estrutura profunda a partir das formas da superfície (Heinz, Kobele e Riggle 2009, 277). A grande e revolucionária mudança provocada por esta teoria dá-se pelo seu interesse principalmente nas formas do output (Schreuder 2004, 3). os processos estruturais da língua (e no nosso caso da música) são derivados da análise das formas resultantes (output) das gramáticas particulares de cada língua (ou estilo musical) (input).

Nesse trabalho é feita uma abordagem segundo um enfoque Sistêmico ou estruturalista, porque pretende-se apreender a música como um sistema de inter-relações, onde cada som faz parte de unidades de sentido maiores, procurando assim reconhecer as estruturas subjacentes em todas as dimensões e relacionando as múltiplas leituras numa visão integradora. Por sua vez, esta abordagem aspira ser não atomizadora ou integradora, porque pretende, ao invés da teoria musical tradicional ocidental, analisar a música desde uma multiplicidade simultânea de suas dimensões que se entrecruzam, influenciando e sendo influenciadas. Finalmente, o enfoque é fenomenológico, porque se propõe analisar o objeto segundo a percepção do ouvinte, baseado em trabalhos como os de P. Schaeffer e M. Chion. A chamada escuta reduzida ${ }^{2}$ fenomenológica provê dados absolutos apreendidos em

1 A partir disso é possível inferir que a música compartilha de maneira sistêmica processos estruturais com outras atividades mentais. Isto permite considerar que o estudo da música não seja o estudo de um objeto isolado e afastado de outras atividades humanas.

2 Escuta reduzida [...] atitude de escuta que consiste em escutar o som em si mesmo, como objeto sonoro, abstraindo a sua real proveniência ou suposta, e do sentido que ele aporte. [...] Na escuta reduzida, o que a nossa intenção de escuta visa é o acontecimento que o objeto sonoro é 
percepção pura, com o propósito de descobrir estruturas essenciais dos eventos musicais e as características objetivas próprias delas. Este trabalho não pretende criar propostas analíticas que excluam sistematicamente qualquer informação extra musical, e sim partir do som sem preconceitos, sem exclusão estilística nem julgamento de valores para obter informações criteriosas, objetivas e organizadas para em seguida, se necessário, acrescentar informações de outras disciplinas ou áreas que ajudem a entender o objeto musical como um elemento multisignificativo.

Nessa comunicação descrevem-se primeiramente as ações mentais envolvidas no processo cognitivo, assim como também os limites humanos para a interpretação e compreensão dos eventos sonoros e das estruturas musicais. Em seguida desenvolvem-se os quatro critérios analíticos e aplicam-se, com intenções didáticas, a excertos de obras musicais de diferentes gêneros e épocas. Em continuação, oferece-se uma guia para a orientação da pesquisa analítica. Finalmente, a conclusão oferece algumas apreciações significativas, toda vez que demonstra que o encontro da análise musical e as ciências cognitivas oferecem uma ferramenta válida, funcional e prática para a abordagem da interpretação da música, além de ser um amplo e novo campo de pesquisa tanto da música como objeto particular, quanto das nossas capacidades mentais.

\section{0 processo cognitivo}

As características do processo cognitivo envolvido estão caracterizadas pelo estudo:

- das leis que descrevem o processo de organização dos estímulos externos, como a Gestalt e seus desdobramentos posteriores, e sua aplicação na música,

- dos processos de direcionamento da atenção em relação a quantidade e qualidade3 ${ }^{3}$, complexidade e simplicidade, originalidade ou repetição e níveis semânticos da informação,

- dos processos de categorização, padronização e semelhança-diferença entre agrupamentos,

- das estruturas na música e a interpretação de suas relações hierárquicas,

- da quantidade e qualidade de informação, em relação a limites cognitivos como o gargalo serial (Anderson, 2004), dos limites da capacidade de proces-

\footnotetext{
- em si (e não para o qual remete), são os valores que ele aporta em si (e não aqueles dos quais é o suporte) (Schaeffer 2007, 63).

3 Quando se fala em quantidade de informação, fala-se na variabilidade da informação significativa possível de ser mensurada em escalas e as relações dessas medidas com a percepção. Já o estudo da qualidade da informação baseia-se no estudo das variações de categoria, conceito ou identidade para avaliar variáveis significativas.
} 
samento da informação (Miller, 1956), ou da janela de presente psicológico ou presente perceptivo (Krumhansl, 2000, Fraisse apud Bigand, 2001)

Estas constantes cognitivas permeiam tanto a criação musical quanto outras áreas da expressão humana justificando a música, não como um evento isolado e sim como uma forma de expressão que compartilha de maneira sistêmica processos estruturais com outras atividades mentais, como por exemplo a lingüística.

\section{Os quatro critérios analíticos}

A leitura da superfície musical de uma obra é feita através de critérios analíticos aplicados a quatro pontos:

1. A textura musical.

2. A segmentação e reconhecimento de padrões na análise do fluxo musical.

3. A relação entre fenômenos de tensão - distensão (resolução) e processos cadenciais na música.

4. A análise da superfície musical nos parâmetros perceptivamente mais significativos.

1. A textura musical. A textura musical estuda-se como resultado da matéria sonora e sua organização, em função dos planos sonoros ${ }^{4}$ (ou PSs -PS no singular) e da maneira como estes se relacionam. Quantidade de planos sonoros, hierarquias e critérios de relacionamento entre os planos e seu comportamento no tempo fornecem dados significativos para a interpretação da estruturação das texturas de um trecho ou obra musical. Por sua vez são analisadas as relações interdimensionais de contexto musical, como objetivo de apreender as múltiplas relações que se estabelecem na música como um todo sistêmico. Finalmente considera-se a variável complexidade - simplicidade e sua resultante perceptiva de tensão relaxamento, e a variável permanência - mudança em função da evolução temporal na relação da textura com a forma musical.

2. A segmentação e reconhecimento de padrões na análise do fluxo musical. Estudo sobre agrupamento (grouping) e segmentação do fluxo sonoro. Estudam-se os processos de segmentação, integração - segregação, categorização e a deteç̧ão de padrões nas cadeias perceptivas auditivas e sua relação com a forma musical. Criam-se critérios analíticos para (1) o processo de integração e segmentação em música, (2) a detecção de padrões em diferentes dimensões de um trecho musical e (3) para o estudo da relação dos pontos anteriores com a forma musical como um todo. Para isto, consideram-se alguns processos mentais que intervêm na

4 Derivados do conceito de cadeias perceptivas de Bregman (1999). 
interpretação dos estímulos auditivos e algumas teorias que desenvolvem os princípios perceptivos em forma de leis. Aborda-se ainda a idéia de detecção de padrões aplicada a parâmetros não convencionais como timbre, modos articulatórios ou intensidades, e a avaliação de suas inter-relações multidirecionais.

3. A relação entre fenômenos de tensão - distensão (resolução) e processos cadenciais na música. Estudo da relação entre as variações do fluxo sonoro e os efeitos de tensão - relaxamento (distensão) perceptíveis pelo ouvinte. Parte-se da hipótese de que, na música, a sensação de tensão (e sua resolução) podem estar relacionadas, em algumas situações, à variabilidade da informação em determinados parâmetros. 0 estudo das variações de fluxo sonoro se realiza sobre três parâmetros: Amplitude, Densidade de eventos e Freqüencia. Estuda-se previamente o conceito de processo cadencial para melhor compreender a importância das cadências como pontos articulatórios do discurso musical, e como elas contribuem na organização perceptiva do fluxo sonoro.

4. Estudo das dimensões sonoras segundo Levitin. Levitin (2007, 22-4) aponta que altura, ritmo, tempo, contorno, timbre, volume, localização espacial e reverberação são as dimensões audiveis numa música. Esta abordagem proporciona elementos analíticos para entender como o grau de variabilidade da informação dentro de cada dimensão se reflete na formalização de uma peça musical. Como ferramenta analítica, propõe-se o uso do conceito de pares de opostos (conceitos de bipolaridade que servem para descrever o comportamento dos parâmetros do som como: regular - irregular, homogêneo - heterogêneo, crescente - decrescente e contínuo - descontínuo).

Em resumo, procurou-se maneiras de analisar a textura, reconhecer os planos sonoros, as hierarquias e vínculos entre eles, analisar a segmentação, agrupamentos e reconhecer padrões nos planos sonoros, individual e coletivamente; analisar as características e comportamento dos materiais da superfície musical para determinar suas configurações; e analisar os pontos de tensão-resolução no fluxo sonoro a partir da percepção auditiva, com o escopo de estabelecer maneiras de interpretar, descrever, classificar, categorizar e organizar a forma musical e seu desenvolvimento na variável tempo.

\section{Exemplos aplicados}

Item 1. De análise de texturas. Análise dos planos sonoros e da relação de subordinação (figura - fundo) entre eles em Guinnevere, de Crosby, Stills and Nash, entre 3:03 min. e 3:36 min. 


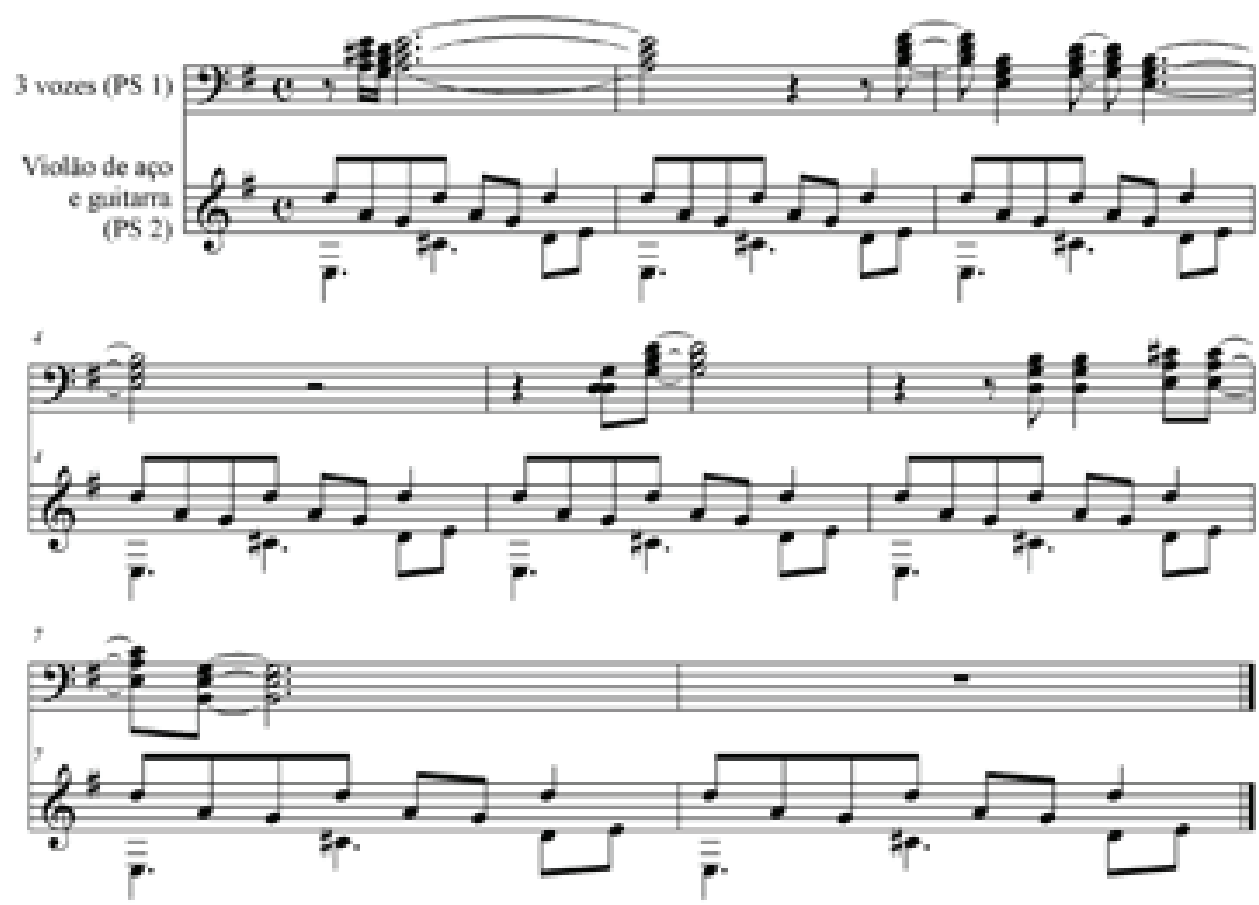

Figura 1: vozes e instrumentos entre 3:03 min. e 3:36 min. de Guinnevere.( transcrição nossa)

$\mathrm{Na}$ transcrição acima observam-se dois planos sonoros: PS1 e PS2. 0 PS1, que possui um tipo de informação diferenciada e com mais capacidade de chamar a atenção, toda vez que o texto cantado possui um nível semântico ${ }^{5}$ superior ao PS dos instrumentos, é a figura que se hierarquiza perceptivamente por sobre o fundo da trama instrumental. Formado por vozes em uma configuração textural de linhas integradas, aparecem assim a nossa percepção porque compartilham de uma série de princípios:

1. rítmicos: os três PSs articulam juntos e possuem a mesma configuração de valores de duração,

2. tímbricos: as três vozes masculinas tem uma qualidade tímbrica semelhante e homogênea e por ocuparem um âmbito intervalar pequeno,

3. e fundamentalmente porque pode-se inferir um objetivo claro por parte dos intérpretes de estabelecer um vínculo que as unifique em um único objeto. Por causa disto (e pela habilidade dos intérpretes) é difícil determinar perceptivamente neste trecho se há alguma delas que possa ser caracterizada como mais importante ou de maior hierarquia perceptiva.

O PS2, no entanto, está formado por uma trama de instrument os de cordas (violão de aço e guitarra elétrica) em que vários padrões (semelhantes, porém não

5 Por nível semântico entende-se a capacidade de transmissão de significados por parte do texto que está sendo cantado pelas vozes que neste caso constituem o PS 1 . 
iguais) executados por cada um dos instrumentos, se escutam integrados como em um tecido, no qual os diferentes princípios individuais rítmicos, de contornos e acentuais dos padrões se complementam. Esta integração se vê reforçada pelas características dos timbres dos instrumentos utilizados, com notas com uma leve sustentação, com ataque firme e abundantes transientes (cordas pulsadas com dedos ou palheta).

Item 2. De segmentação, estruturação hierárquica em cinco níveis e de reconhecimento de padrões no Parabéns pra você.

\footnotetext{
nível 1 - peça

completa (obra)

nível 2 - frases (A

e B)

nível 3 - semifrases ou grupos ( 1 , 2,3 , e 4) marcados por linhas contínuas

nível 4 - grupos marcados por triángulos tracejados

nivel 5 - notas individuais
}

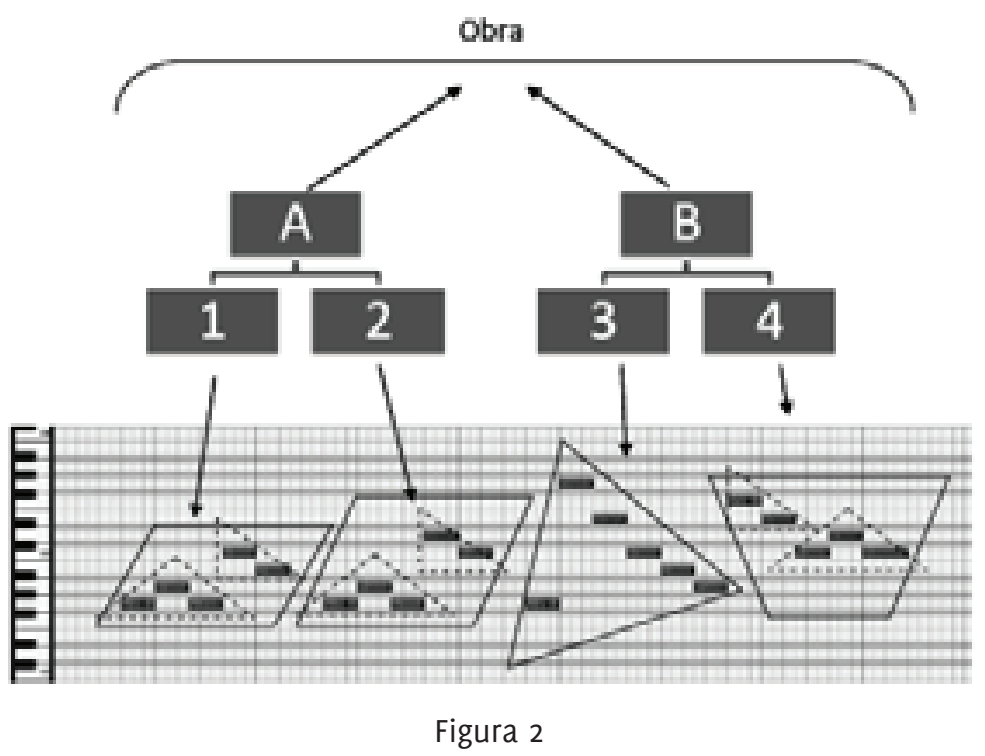

A figura 2 serve como representação dos cinco níveis, desde a nota individual à obra completa na peça citada. No nível 3, que corresponde aos grupos de núme$\operatorname{ros} 1,2,3$ e 4 (inseridos no retângulo tracejado), encontram-se os padrões. Estes padrões tem, como conjunto de sons inter-relacionados sistemicamente, características emergentes, que os caracterizam. ${ }^{6}$ Uma vez caracterizados pode-se realizar análises como o de igualdade - diferença entre padrões.

6 Denominam-se aqui características emergentes às características informacionais que surgem a partir do agrupamento de elementos. Estas características não fazem parte de nenhuma das unidades individualmente, porém emergem como resultado do agrupamento. Por ex. uma bicicleta tem como característica emergente a função de meio de transporte, embora nenhuma das suas partes por separado tenham essa função. 
Item 3. De categorização e análise de igualdade - diferença entre padrões.

\begin{tabular}{|c|c|c|c|c|}
\hline & Grupo 1 & Grupo 2 & Grupo 3 & Grupo 4 \\
\hline Anacruse & \multirow{10}{*}{ 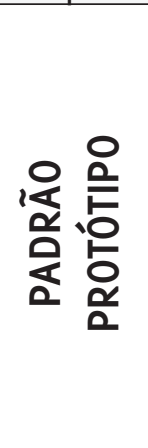 } & I & I & - \\
\hline Ritmo & & I & + & I \\
\hline Acentuação da frase & & I & I & I \\
\hline Duração total & & I & + & I \\
\hline Durações individuais & & I & I & I \\
\hline Subdivisão & & I & $\mathrm{D}$ & + \\
\hline Pausa final & & I & $\mathrm{D}$ & I \\
\hline Alturas absolutas & & + & D & - \\
\hline Intervalos dos subgrupos & & I & D & I \\
\hline Intervalos de enlace entre subgrupos & & D & $\begin{array}{c}\text { D } \\
\text { (Não existe) }\end{array}$ & D \\
\hline
\end{tabular}

Referências: I sobre fundo preto = igual

+ sobre fundo cinza claro = mais semelhante

- sobre fundo cinza claro $=$ menos semelhante

D sobre fundo branco $=$ diferente

0 quadro acima representa a relação igualdade, semelhança e diferença nos padrões reconhecidos no nível 3 do Parabéns pra você. Dez parâmetros de confronto servem para determinar a relação de igualdade - diferença entre os padrões. No caso da figura 3 é possível afirmar que o grupo 2 é mais parecido ao grupo 1 (denominado de padrão protótipo) que serve como exposição do material, melódico, rítmico e intervalar. 0 grupo 3 é o mais distante do grupo 1 , enquanto 0 grupo 4 coloca-se numa situação intermediária. Este tipo de leitura fornece dados que permitem interpretar uma relação estrutural entre os elementos integrantes da peça.?

Item 4. De estudo da relação forma com a variabilidade de fluxo sonoro na dimensão amplitude, aplicado a Bohemian Rhapsody, de Queen.
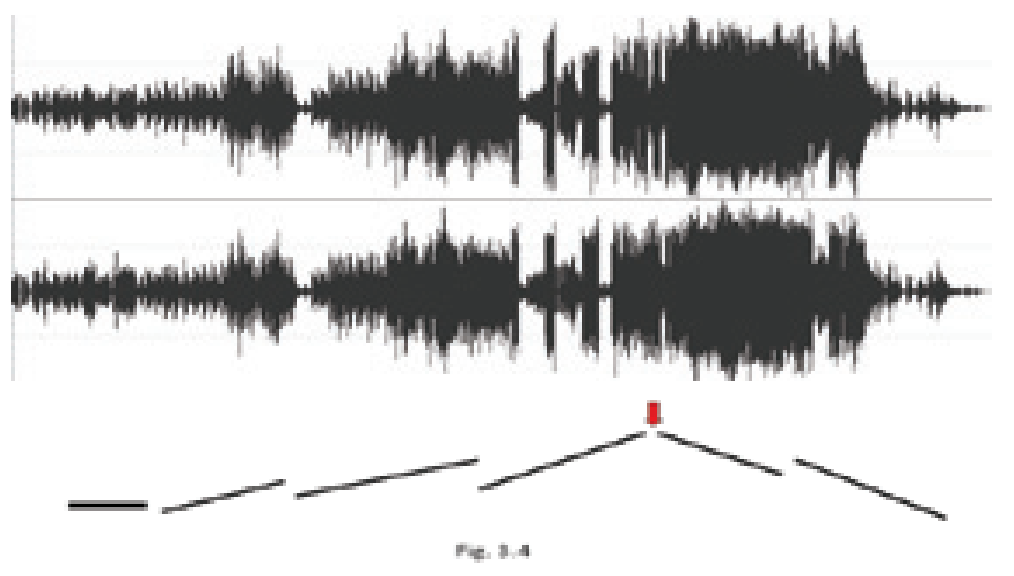

Figura 4: sonograma e linhas simplificadas do fluxo de tensão por amplitude na música.

7 No trabalho de referência (pag. 89-92), é demonstrado que outras obras podem possuir uma estruturação material e formal análoga a esta, permitindo a comparação entre o Parabéns pra você e obras de maior envergadura como o Prelúdio op. 28 no. 7 em Lá Maior, para piano de F. Chopin. 
0 sonograma (obtido a partir de softwares como Sound Forge) permite corroborar a existência de um processo crescente até a ponto de maior tensão (ou clímax, marcado com uma seta na figura) e sua conseqüente diluição até o repouso, coincidente com a tensão perceptiva.

Item 5. Da análise de Densidade de eventos por unidade de tempo. Na figura 5 , que corresponde a Renegade master (Fatboy slim old skool mix), podemos perceber que 0 acúmulo de maior quantidades de eventos por unidade de tempo funciona como processo de aumento de tensão perceptiva,

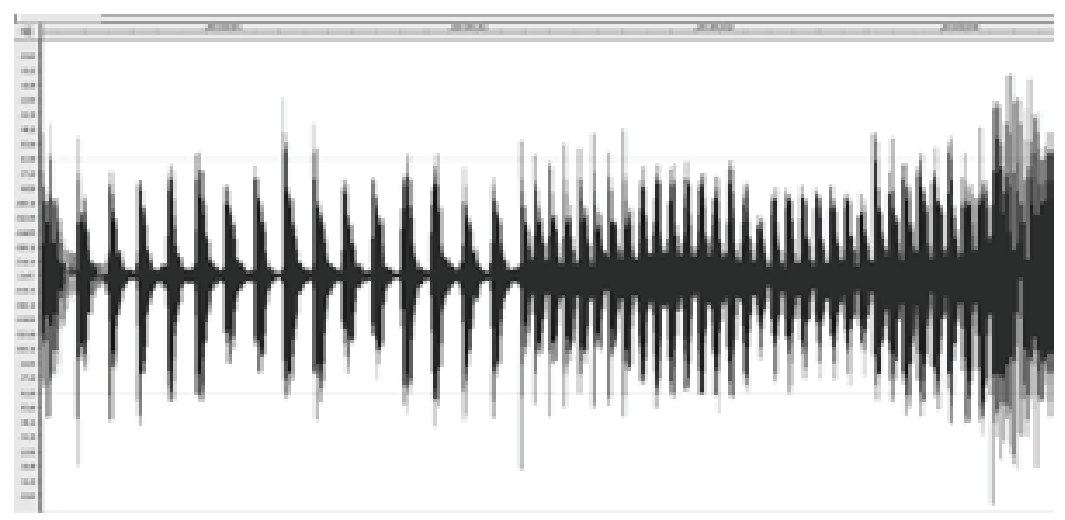

Figura 5: sonograma que mostra o aumento de densidade de eventos funcionando como processo cadencial em Renegade master.

e na seção A (exposição, compassos 1-32) do segundo movimento da Sonata para piano opus 2 no. 1 de Beethoven (figura 6), na qual o computo de eventos por unidade de tempo (neste caso o compasso) permite observar como este recurso é usado na criação de pontos cadenciais de tensão e distensão.

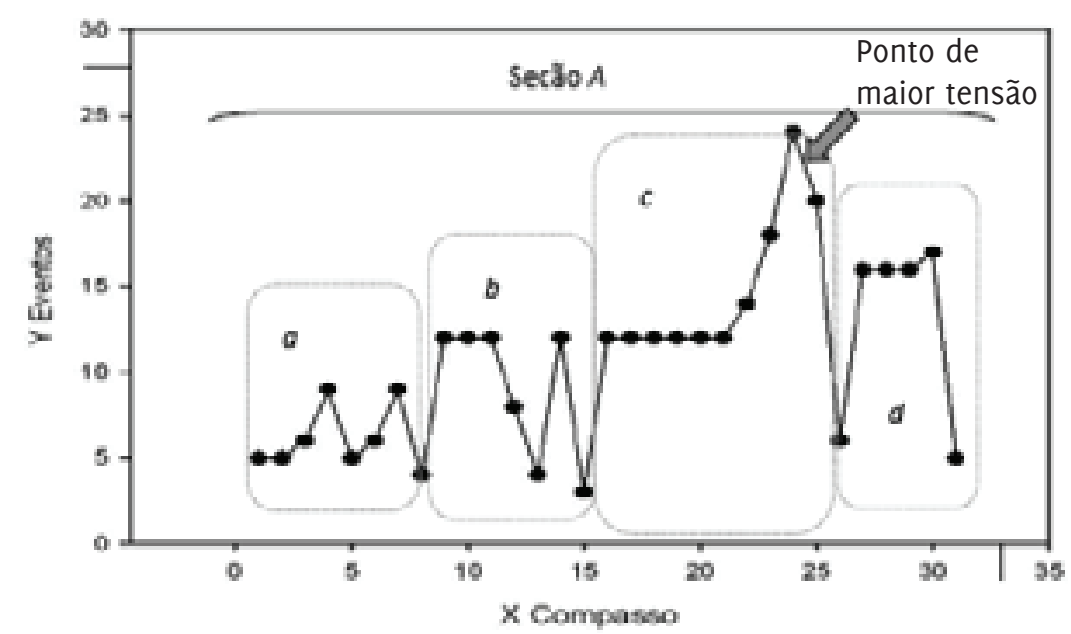

Figura 6: gráfico que contabiliza a Densidade de Eventos por unidade de tempo (no caso utilizou-se o compasso como unidade) para confrontar o aumento de tensão em relação ao aumento quantitativo de ataques. 
Item 6. Do estudo da superfície musical na dimensão contornos melódicos a partir dos pares de opostos, em The first circle de Pat Metheny Group, entre 1:50 e 2:29 min.

Fazendo-se uso dos pares de opostos, analisa-se a superfície sonora de uma obra em procura de processos estruturais.

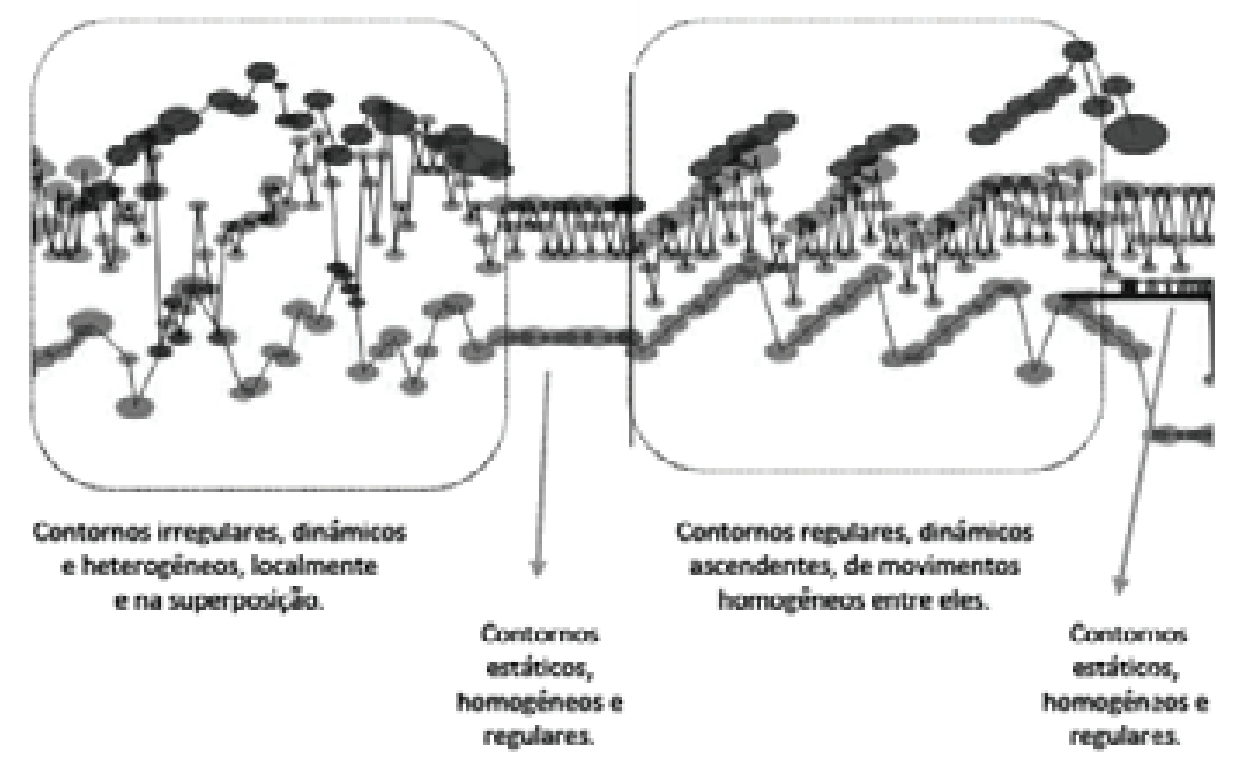

Figura 7: análise dos contornos melódicos na música em representação segundo o programa MAM Player. ${ }^{8}$

$\mathrm{Na}$ figura 7 podem-se observar dois trechos (marcados com quadrados tracejados) que possuem características perfeitamente descrevíveis a partir dos pares de opostos. Estas unidades formais aparecem conectadas entre si por uma outra pequena unidade formal que também possui características próprias, do mesmo modo que o trecho musical que relaciona seqüencialmente a segunda unidade remarcada com a sua continuação (não detalhada na figura).

\section{Orientação da pesquisa analítica}

Para o uso dos critérios analíticos aqui descritos, criou-se um direcionamento para sua aplicabilidade, baseado em uma série de perguntas que podem ajudar na prática analítica e direcionam a pesquisa.

Das texturas em geral:

80 MAM Player é um software livre que permite a visualização gráfica de arquivos MIDI em vários modos. Para mais informações sobre o MAM Player ver: http://www.musanim.com/player/ 
- Qual é a relação da textura do trecho/peça com a forma musical como um todo?

- 0 trecho/peça analisado possui um único tipo de textura, ou mais de um?

- Como se configuram as texturas em relação às unidades formais?

- Como isso se reflete perceptivamente?

- Sobre as texturas em particular:

- Quantos planos sonoros se percebem?

- Todos eles são percebidos com a mesma importância ou hierarquia?

- Como é a relação entre os planos sonoros segundo os critérios de integração subordinação - independência?

- As situações texturais percebidas são estáticas ou dinâmicas?

- Qual a incidência perceptiva do comportamento das texturas em geral e em particular?

- Sobre a segmentação dos planos sonoros e detecção de padrões:

- Os planos sonoros podem ser segmentados?

- Uma vez segmentados, é possível segmentar os planos sonoros internamente, criando assim níveis, como uma estrutura hierárquica até chegar ao nível dos sons como objetos individuais indivisíveis?

- É possível perceber configurações ou modelos de segmentação que representem algum tipo de comportamento ou organização?

- Quais os critérios de organização perceptiva que justificam e interpretam a segmentação da construção sonora?

- Se existir mais de um plano sonoro simultâneo, a segmentação deles é igual ou diferente? Qual a relação entre eles? Qual o resultado perceptivo disto?

- É possível determinar um nível no qual se encontram padrões, definíveis como objetos característicos, que se apresentam como elementos significativos?

- Como são esses padrões? É possível descrevê-los? Quais categorias os descrevem de maneira suficiente?

- Existe alguma relação entre os padrões? É possível estabelecer relações de semelhança ou diferença entre eles?

- Como é o comportamento dos padrões no tempo, e como isto influencia a forma musical?

- É possível fazer uma análise multidirecional entre planos sonoros simultâneos e/ou sucessivos?

9 Unidade formal: unidade de sentido que possui em si mesmo características distintivas para ser autoreferentes, de autocompletamento e que permitem identificá-la como uma entidade formal. (Falcón 2011, 173) 
- Como são as reações estruturais e formais entre planos/dimensões sonoras diferentes (ou múltiplas) em um trecho/peça musical?

- É possível inferir estruturas formais baseadas nos critérios de segmentação e de comportamentos dos padrões?

- Sobre o estudo da relação tensão - distensão e os processos cadenciais no fluxo musical:

- É possível observar nos parâmetros amplitude, densidade de eventos e freqüência, algum tipo de comportamento que participe ativamente na criação de pontos destacáveis perceptivamente em termos de tensão - repouso?

- Como estes pontos perceptivamente hierarquizados, resultantes do comportamento dos materiais, se articulam no fluxo sonoro do trecho/peça analisado?

- Sobre o estudo dos parâmetros perceptivamente mais significativos:

- É possível estabelecer critérios de comportamento, em termos de pares de opostos nos parâmetros descritos por Levitin como os mais importantes perceptivamente?

- Como é o comportamento dos parâmetros em relação à forma musical?

- É possível estabelecer alguma relação entre o estudo dos limites cognitivos da percepção e a maneira que a superfície musical está configurada?

\section{Conclusão}

Neste trabalho propõem-se algumas direções que pretendem conjugar à análise musical junto ao estudo da cognição humana. Este hibridismo gera um intercâmbio que posiciona o pesquisador em direção a uma abordagem prática, abrangente (por não ter exclusão estilística nenhuma), que não precise de conhecimentos de alta especificidade e direcionada à uma das mais básicas maneiras de relacionar-se com a música: escutando-a. Muitas vezes a informação obtida por cada um dos critérios analíticos expostos é compartilhada por mais de um dos critérios, influenciando, sendo influenciada e gerando um cruzamento que enriquece e aumenta consideravelmente a compreensão do objeto de estudo, o que é conjecturado desde nosso ponto de partida, por considerarmos a música como um fenômeno sistêmico. Nesse processo o objeto (a música) e ferramenta (a cognição) podem intercambiar suas funções permitindo aprender tanto da música como de nós mesmos e de nossas capacidades. Ao mesmo tempo, mostra-se que esse intercâmbio inter-dimensional se espelha no intercâmbio extra musical, na interação gerada entre a música e outras disciplinas ou comportamentos humanos, fato que legitima a idéia de que a música é um fenômeno elementar para o ser humano. Logo, se a música é tão elementar para o ser humano, o estudo dela será, conseqüentemente, muito significativo, porque nos dirá como nós somos. 


\section{Referências Bibliográficas}

> ANDERSON, John. R. Psicologia cognitiva e suas implicações experimentais. Rio de Janeiro: LTC editora, 2004. 307 p.

$>$ BIGAND, Emanuel. Contributions of musical research on human auditory cognition em Thinking in sound: the cognitive psychology of human audition, editado por Stephen McAdams e Emmanuel Bigand. London: Oxford University Press, 2001. p. 231-273.

> BREGMAN, Albert. Auditory scene analysis. London:The MIT Press, 1999. 773 p.

> FALCÓN, Jorge A. Quatro Critérios Para a Análise Musical Baseada na Percepção Auditiva. 2011. Dissertação de Mestrado, Universidade Federal do Paraná, Curitiba. 177 p. Disponivel em http://ufpr.academia.edu/JorgeFalcon/Papers/603899/ QUATRO_CRITERIOS_PARA_A_ANALISE_MUSICAL_BASEADA_NA_PERCEPCAO_AUDITIVA. Acesso em: 12 de outubro de 2011

> HEINZ, Jeffrey, Gregory Kobele e Jason Riggle. Evaluating the complexity of Optimality Theory, Linguistic Inquiry, Vol. 40, No. 2, 2009. P. $277-88$.

$>$ KRUMHANSL, Carol. Rhythm and pitch in music cognition. Psychological Bulletin, vol 126, no. 1, 2000. p.159-79.

> LEVITIN, Daniel. Uma paixão humana. 0 cérebro e a música. Lisboa: Editorial Bizancio, 2007. $331 \mathrm{p}$.

> MILLER, George. The Magical Number Seven, Plus or Minus Two: Some Limits on Our Capacity for Processing Information. The Psychological Review, vol. 63, 1956. p. 81-97

> SCHAEFFER, Pierre. Solfejo do objecto sonoro. Tradução de António de Sousa Dias. Paris: INA - GRM - Groupe de recherches musicales, 2007. 83 p.

> SCHREUDER, Maartje. Conflicting constraints in language and music. Dissertação de Mestrado. University of Groningen,Department of Linguistics, 2004.

> THORESEN, Lasse. Form-building transformations: an approach to the aural analysis of emergent musical forms. JMM: The Journal of Music and Meaning, vol.4, Winter, 2007. Disponível em http://www.musicandmeaning.net/issues/ showArticle. php?artID =4.3. Acesso em: 19 de fevereiro de 2011. 
Referências em áudio

> QUEEN. Bohemian rhapsody. F. Mercury, A night at the opera, CD, EMI, 1975.

$>$ CROSBY, STILLS AND NASH. Guinnevere. D. Crosby. Crosby, Stills and Nash, CD, 7567-82651-2, Atlantic, 1994.

> PAT METHENY GROUP. The first circle. L. Mays. P. Metheny. First circle. CD, 823342-2, ECM, 1991.

> FATBOY SLIM. Renegade master (Fatboy Slim old skool mix). R. Mackenzie. Renegade master (Remixes), CD, 21,Ultra Records, 1998.

Jorge Alberto Falcón

jorgef@musician.org, jorgitofalcon@hotmail.com 